\title{
Effect of Construction Minor Defects on the Ductility of Reinforced Concrete Drilled Shafts
}

\author{
Sami W. Tabsh ${ }^{1}$ \\ ${ }^{1}$ American University of Sharjah \\ Sharjah, United Arab Emirates \\ stabsh@aus.edu
}

\begin{abstract}
Reinforced concrete drilled shafts are a form of deep foundation that is capable of resisting large axial forces, shears and bending moments. They are commonly used in long span bridges and high-rise buildings because of their economy. Since they are cast below ground level, they can be exposed to different construction defects in the form of soil inclusions and steel cage offset. Nonedestructive testing is often used for quality assurance purposes, but such techniques can only detect moderate to large flaws. In this research, one intact and five defective shafts are tested in the structural laboratory under pure axial compression to determine the effect of voids, out-of-position of steel cages and steel bar corrosion on ductility. Two types of voids equal to $15 \%$ of the shaft's cross-sectional area are considered, one forming within the concrete cover and the other penetrating inside the concrete core. The $1830 \mathrm{~mm}$ long shafts had a $305 \mathrm{~mm}$ diameter; they were tested under displacement-controlled condition inside a universal test machine. Findings of the study showed that the presence of minor defects has little effect on the structural behavior within the service load level, but great impact on the ductility. Also, the impact of a deep void or corroded reinforcement through a surface void on the ductility is much more significant than that of a surface void or steel cage offset.
\end{abstract}

Keywords: Anomaly, axial compression, corrosion, defect, drilled shafts, ductility, steel cage offset.

\section{Introduction}

Structures are supported on the ground by foundation whose job is to safely transfer the gravity and lateral loads from the superstructure to the soil and provides stability to the structure. In general, a foundation can be classified as either shallow or deep, in relation to the depth at which the foundation is placed. There are differences between deep and shallow foundation with regard to their cost, feasibility, load transfer mechanism, advantages, disadvantages, types etc. A shallow foundation is often cheaper and easier to construct than deep foundation. Shallow foundation transfers load mostly by end bearing, whereas deep foundation rely both on end bearing and skin friction [1].

Drilled shafts or piers, piles and caissons are all examples of deep foundation. There are many advantages of deep foundation including the ability to carry large compressive loads through water and poor material to firm strata, providing lateral support, and resisting uplift. They are used when pile-driving vibrations and noise are prohibited, pile capacity is insufficient for the applied load and large end-bearing areas are required for increased axial capacity. Compared to shallow foundation, deep foundation is more expensive, needs skilled labor, involves complex construction procedures, requires special construction equipment, and takes a lot of time to build.

Drilled shafts are constructed in the field by excavating long cylindrical holes into the ground, inserting steel cages made up of longitudinal and transverse bars into them, and filling them with concrete, as shown in Fig. 1. They often range in diameter from $0.5 \mathrm{~m}$ to $3.0 \mathrm{~m}$ or more and can be installed to depths in excess of $100 \mathrm{~m}$. They are commonly used to support high-rise buildings, long-span bridges, and retaining walls, and also to stabilize landslides. Drilled shafts can be an economic solution for a variety of difficult ground conditions because they resist large lateral and axial forces, including tension. 



Fig. 1: Basic construction sequence for drilled shafts.

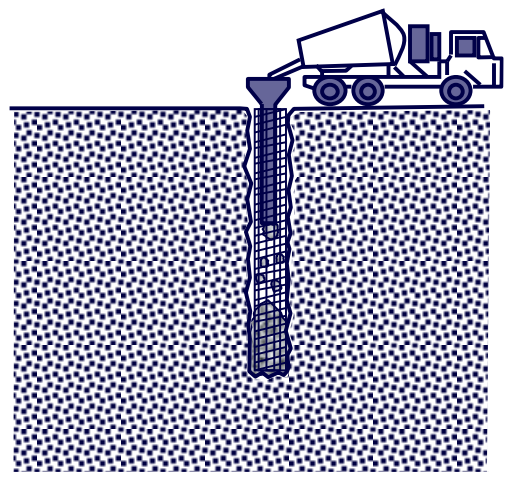

Iskander et al. [2] addressed widespread anomalies in drilled shafts, their method of detection and effect on strength. The study showed that minor defects had little effect on skin friction; a soft bottom resulted in a 33\% reduction in end bearing relative to a sound bottom; and reloading a shaft can result in a 20-30\% reduction in the geotechnical capacity. As part of a research team, the author has investigated the effect of soil inclusion in drilled shafts on the structural capacity using experimental and computational approaches on shafts containing voids [3-7]. Both surface and deep void defects having a size equal to $15 \%$ of the cross-sectional area were embedded inside scaled shafts before experimental testing. In general, the results showed that shafts with superficial voids have minor impact on the strength, but shafts containing voids penetrating into the concrete core experienced maximum strength reductions equal to $22 \%$ for shear, $33 \%$ for flexure and $27 \%$ for eccentric axial compression, when compared with the corresponding intact shafts. Later, Hajali and Abishadid [8] conducted similar tests on shafts but with much larger void defects, reaching up to $40 \%$ of the shaft's cross-sectional area, and causing the axial load carrying capacity to reduce by almost $50 \%$.

Previous studies on drilled shafts have considered common defects in drilled shafts, detection techniques and their effect on the load-carrying capacity but not ductility. Ductility is a measure of the level to which a structure can undergo large deformations before collapse. An example of a ductile structure is a well-detailed reinforced concrete flexural member having tensile strain in the extreme tension steel reinforcement layer larger than 2.5 times the yield strain [9], resulting in ample warning prior to collapse as expressed by excessive deflection and cracking. In current design codes and specifications, structures that can fail in a ductile manner are rewarded with a large strength reduction factors, which results in economy.

\section{Objective and Scope}

The main objective of this study is to investigate the effect of common types of construction defects in reinforced concrete drilled shafts on the structural ductility. To do so, six one-third scale model shafts are tested in the structural laboratory without the surrounding soil under concentric axial compressive loading. The considered defects are voids, steel cage shifting, and longitudinal rebar corrosion. The research addresses two types of voids, one that occupies the concrete cover (referred to as "Surface") and another penetrates into the core (referred to as "Deep). In plan, all voids have an area equal to $15 \%$ of the cross-sectional area of the shaft, which is determined to be the smallest void size that can be detected by NDT testing [10]. Along the shaft centerline, two void lengths are considered, one equal to one-half the shaft diameter (referred to as "Short") and another one equal to the shaft diameter (referred to as "Long"). Figure 2 shows the geometry of the voids considered in the study. 


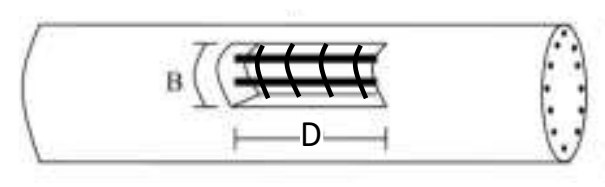

Long Void

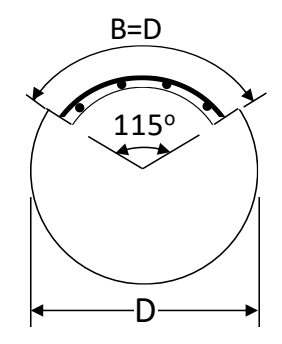

Surface Void

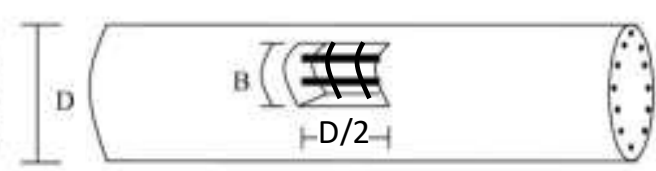

Short Void

Fig. 2: Geometry of the void defects considered in the study.

\section{Experimental Program}

The diameter and length of the tested shafts are respectively $305 \mathrm{~mm}$ and $1830 \mathrm{~mm}$. The longitudinal reinforcement is 12 imperial No. 4 bars (total steel area $=1550 \mathrm{~mm} 2$ ), except for the shafts that contained corroded steel; in that case 4 imperial No. 3 bars through the void and 8 imperial No. 4 elsewhere are used (total steel area $=1318 \mathrm{~mm} 2$ ). The nominal yield strength of the longitudinal bars is $414 \mathrm{MPa}$. At the time of testing, the concrete compressive strength of $150 \times 300 \mathrm{~mm}$ cylinder ranged between 43 and $45 \mathrm{MPa}$. Transverse steel reinforcement was in the form of spirals consisting of W4 smooth imperial wires (diameter $=5.7 \mathrm{~mm}$ and cross-sectional area $=26 \mathrm{~mm} 2$ ) with $448 \mathrm{MPa}$ nominal yield strength. The six specimens have a spiral spacing (referred to as pitch) equal to $25 \mathrm{~mm}$. The clear concrete cover on spiral is $25 \mathrm{~mm}$, except for the case of steel cage offset which had minimum and maximum clear cover of $13 \mathrm{~mm}$ and $38 \mathrm{~mm}$, respectively. Figure 3 shows typical stress-strain relationships for the longitudinal steel and concrete.

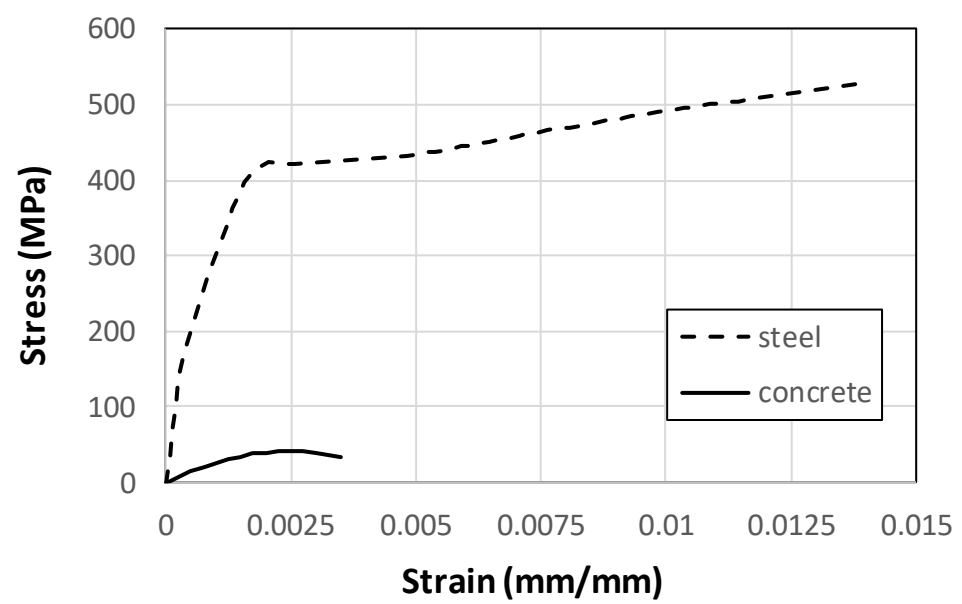

Fig. 3: Typical stress-strain relationships for the longitudinal steel and concrete.

The shafts were placed in a vertical position inside a universal test machine and subjected to concentric axial compression at a rate of $0.25 \mathrm{~mm}$ per minute. They were instrumented with four vertical LVDTs that were uniformly mounted in the middle region of the shaft to measure displacements between two points that were $406 \mathrm{~mm}$ apart. The specimens were confined with steel jackets over a distance of $530 \mathrm{~mm}$ at the loaded and supported edges in order to prevent premature concrete cracking due stress concentration, as demonstrated in Fig. 4. 


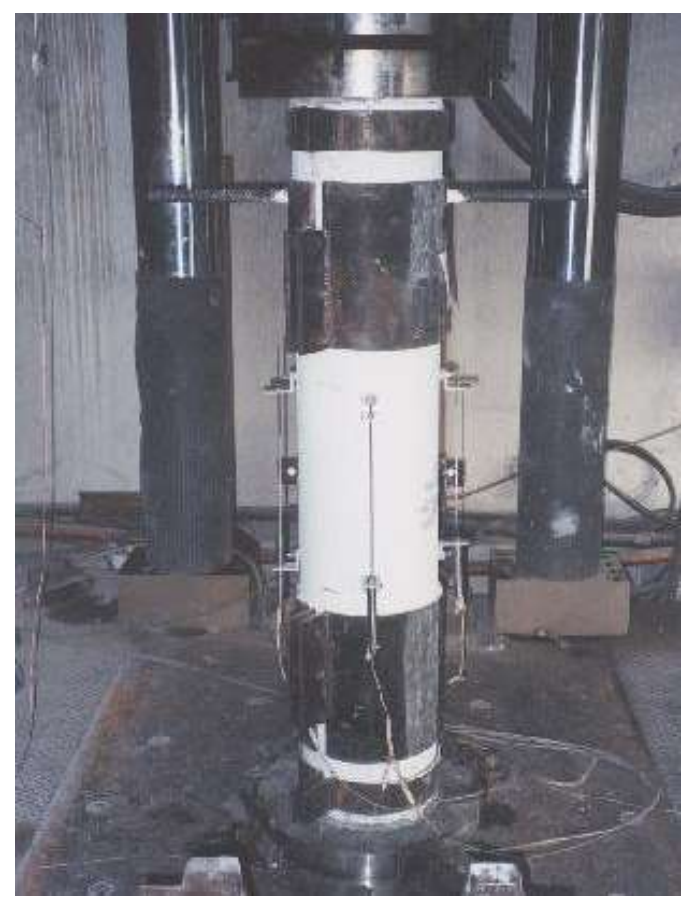

Fig. 4: Test setup and instrumentation.

Table 1 shows details of the six tested specimens. Specimen 1 is the control shaft and referred to as "intact," since it does not contain any defect. The responses of Specimens 1-4 are compared to determine the effect of void defects having different geometry and length. The structural behavior of Specimens 5 and 6 is compared with that of Specimen 1 in order to study effect of steel cage offset and corrosion of reinforcement, respectively.

Table 1: Details of the tested shaft specimens.

\begin{tabular}{|c|l|}
\hline Specimen & \multicolumn{1}{|c|}{ Type of Defect } \\
\hline 1 & None (intact) \\
\hline 2 & Surface, short void \\
\hline 3 & Surface, long void \\
\hline 4 & Deep, long void \\
\hline 5 & 13 mm cage offset \\
\hline 6 & 44\% corrosion in 4 rebars exposed through a surface, long void \\
\hline
\end{tabular}

\section{Ductility}

There are different ways for assessing the ductility of a structural member. The most common way is by dividing the strain corresponding to peak load by the strain corresponding to initiation of yielding in the reinforcement. In this study, however, ductility is measured as the ratio of the strain corresponding to $85 \%$ of the peak load on the descending part of the load-strain diagram, $\left(\varepsilon_{0.85}\right)_{\text {pre }}$, to that on ascending part, $\left(\varepsilon_{0.85}\right)_{\text {post }}$, as shown in Fig. 5 and presented below:

$$
\eta=\frac{\left(\varepsilon_{0.85}\right)_{\text {pre }}}{\left(\varepsilon_{0.85}\right)_{\text {post }}}
$$

The above equation represents a practical approach to measure ductility since the strain in the longitudinal steel bars is nonuniform in the defective shafts due to lack of symmetry in the cross-sectional geometry and/or steel reinforcement. 




Fig. 5: Parameters used in the evaluation of ductility.

\section{Results}

Figure 6 shows crack formations for the defective shafts containing surface deep voids at ultimate condition. It is clear that the presence of a deep void causes the exposed longitudinal steel rebars to buckle at high load level.

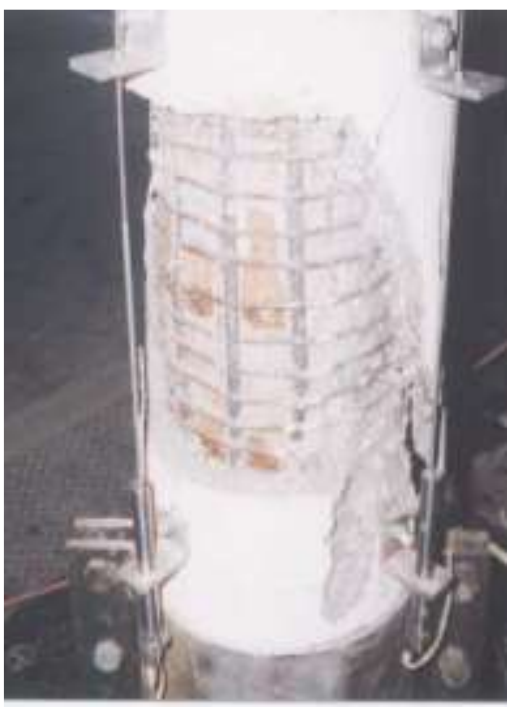

(a)

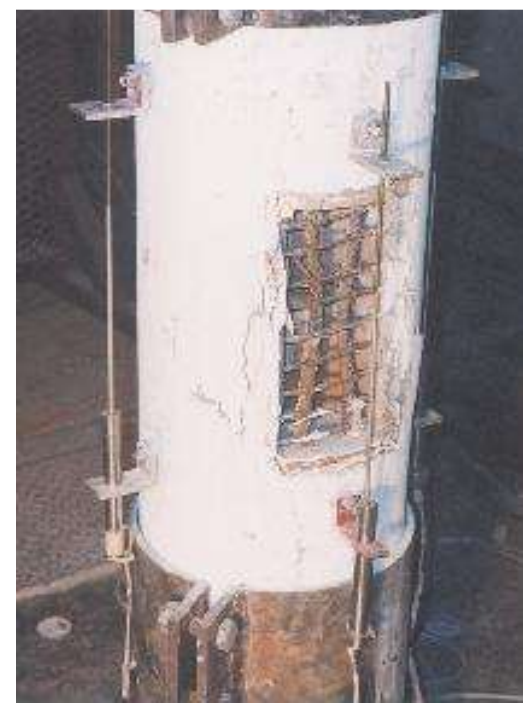

(b)

Fig. 6: Crack formation on the shafts: (a) Specimen 3, and (b) Specimen 4.

Results for the load-strain diagrams for the tested shafts are presented in Fig. 7. They show similar behavior in axial concentric loading up to the ultimate capacity; thereafter, they differ from each other. The results clearly indicate loss of strength for the defective shafts, but the reduction in ductility is more critical especially for the two shafts containing deep voids and corroded reinforcement. Comparison between specimens 1,2 and 3 shows that the length of the cavity along the shaft's length greatly impacts the structural response. While the presence of a short surface void only decreased the strength by $3.4 \%$ and ductility by $3.6 \%$, the presence of a long surface void resulted in reductions of $8.7 \%$ in strength and $40.1 \%$ in ductility. The reduction in ductility is much larger, equal to $66.4 \%$, when the void penetrates deep into the core (Specimen 4). Note that the shaft which contained a small steel cage offset, specimen 5, had a slightly higher strength in axial compression than the intact shaft because it had the highest concrete compressive strength at the time of testing .experienced the least effect on ductility. Specimen 6 which contained 4 corroded rebars that were exposed through a surface, long void had an $8.0 \%$ reduction in strength and $58.6 \%$ reduction in ductility, when compared with the nondefective shaft. Table 2 shows a summary of the findings of the ductility analysis for the intact and five defective shafts. 


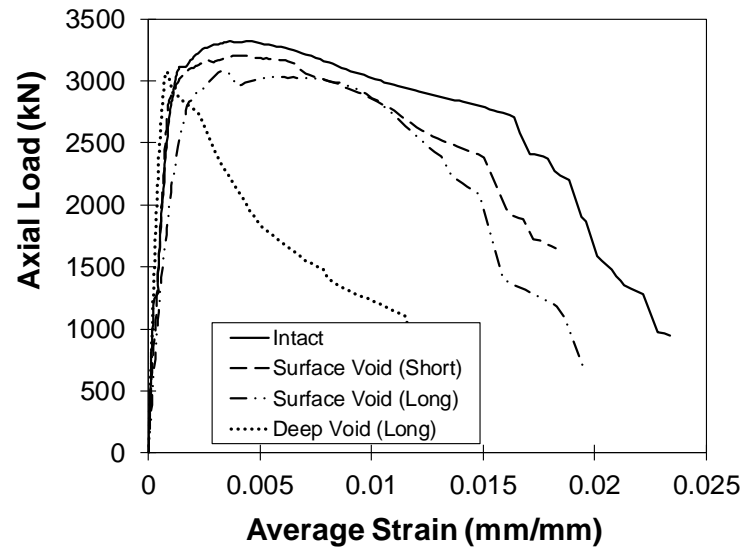

(a)

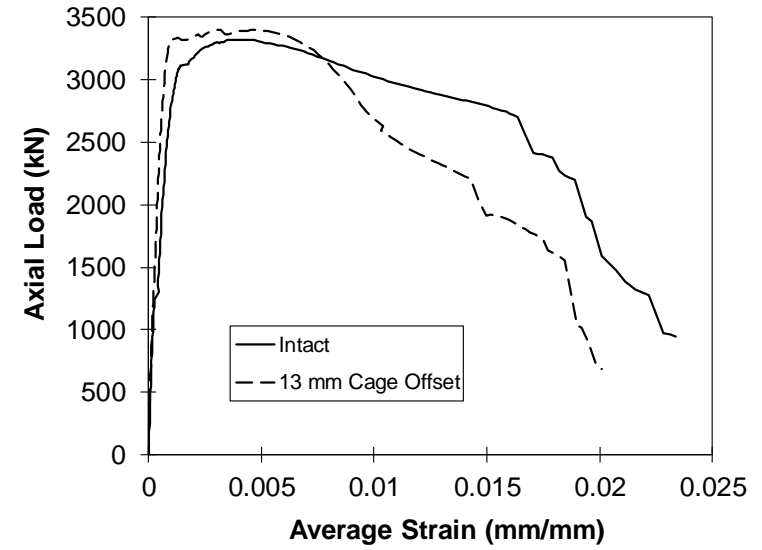

(b)

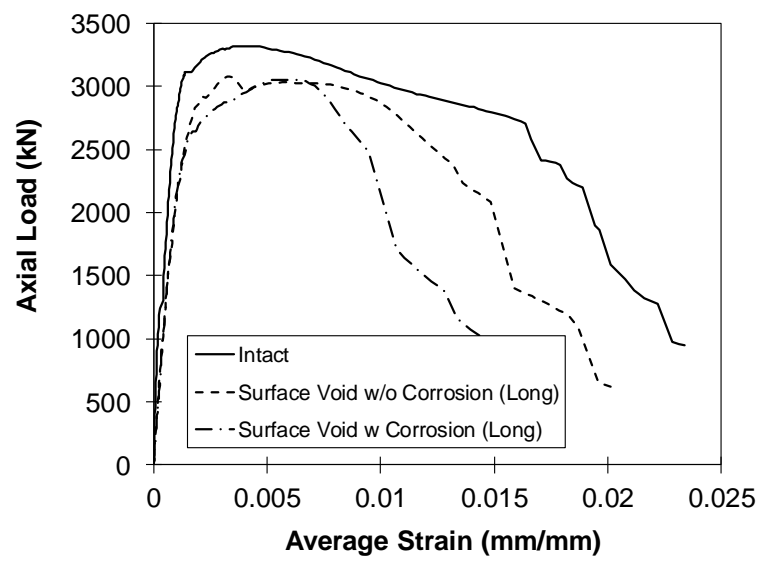

(c)

Fig. 7: Results of load-strain relationships from experimental tests.

Table 2: Ductility analysis of the tested shaft specimens.

\begin{tabular}{|c|c|c|c|c|}
\hline Specimen & $\mathrm{P}_{\max }(\mathrm{kN})$ & $\left(\square_{0.85}\right)_{\text {pre }}$ & $\left(\square_{0.85}\right)_{\text {post }}$ & $\square$ \\
\hline 1 & 3320 & 0.00103 & 0.0143 & 13.9 \\
\hline 2 & 3206 & 0.000834 & 0.0112 & 13.4 \\
\hline 3 & 3031 & 0.00143 & 0.0119 & 8.32 \\
\hline 4 & 3074 & 0.000545 & 0.00255 & 4.67 \\
\hline 5 & 3401 & 0.000663 & 0.00894 & 13.5 \\
\hline 6 & 3054 & 0.00155 & 0.00891 & 5.75 \\
\hline
\end{tabular}

\section{Conclusion}

Results of the study lead to the following conclusions:

1. The presence of minor defects in the form of voids, steel corrosion and cage offset has little effect on the structural behavior within the elastic region of the load-strain relationship.

2. The effect of a minor defect in shafts is more significant on ductility than on axial compressive strength.

3. The impact of a short surface void or small steel cage offset on the ductility of shafts is negligibly small.

4. The effect of a deep void defect or corroded reinforcement through a surface void defect on the ductility is substantial. 


\section{Acknowledgements}

The author would like to thank the late Dr. M.W. O’Neill for contributing to the research and his former students Mr. E. Hammad, Mr. H. Ezzells, Mr. Y. Laham, Mr. N. Ghannam, Mr. P. Mullin, and Mr. S. Kalaga for assisting in the laboratory tests. The experimental component of the research was sponsored by the International Association of Foundation Drilling and a pool of states administered by the Federal Highway Administration.

\section{References}

[1] J. E. Bowles, Foundation Analysis and Design, Fifth Edition, McGraw-Hill, New York, 2001, 1175p.

[2] M. Iskander, D. Roy, S. Kelley, and C. Ealy, "Drilled Shaft Defects: Detection, and Effects on Capacity in Varved Clay," Journal of Geotechnical and Geoenvironmental Engineering, vol. 129, no. 12, 2003, pp. 1128-1137.

[3] S. W. Tabsh and M. W. O’Neill, "Effects of Minor Anomalies on Axial Capacity of Drilled Shafts," Transportation Research Record, No. 1272, Transportation Research Board, NAS, Washington, D.C., 2001, pp. 65-72.

[4] H. Sarhan, S. W. Tabsh, M. W. O’Neill, A. Ata, and C. Ealy, "Flexural Behavior of Drilled Shafts with Minor Flaws," Geotechnical Special Publication No. 116, Deep Foundations, Vol. Two, ASCE, pp. 1136-1150, 2002.

[5] M. W. O’Neill, S. W. Tabsh, and H. Sarhan, "Response of Drilled Shafts with Minor Flaws to Axial and Lateral Loads," Engineering Structures, Elsevier, vol. 25, no. 1, pp. 47-56, 2003.

[6] M. W. O’Neill, H. Sarhan, and S. W. Tabsh, "Structural Capacity Reduction for Drilled Shafts with Minor Flaws," Structural Journal, American Concrete Institute, Detroit, Vol. 101. No. 3, 2004, pp. 291-297.

[7] S. W. Tabsh, M. W. O’Neill, and M. Nam, "Shear Strength of Drilled Shafts with Minor Flaws," Engineering Structures Journal, vol. 27, issue 5, pp. 736-748, 2005.

[8] M. Hajali and C. Abishdid, "Behavior of Axially Loaded Drilled Shafts Foundations with Symmetric Voids Outside and Inside the Caging," DFI Journal, vol. 6, no. 2, pp. 3-12, 2012.

[9] ACI Committee 318, "Building Code Requirements for Structural Concrete and Commentary," American Concrete Institute, Detroit, 2014.

[10] M. M. Samman, and M. W. O'Neill, "The reliability of sonic testing of drilled shafts," Concrete International, American Concrete Institute, vol. 19, no. 1, pp. 49-54, 1997. 